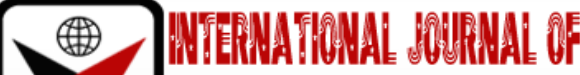

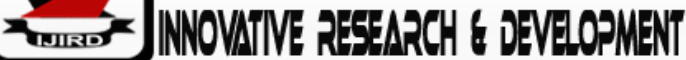

ISSN 2278-0211 (Online)

\section{Determination of Antimalarial Property, Chemical Constituents and Toxicity Level of Alstoniaboonei Aqueous Stem Bark Extract in Plasmodiumberghei Infected Mice}

\begin{tabular}{|c|}
\hline 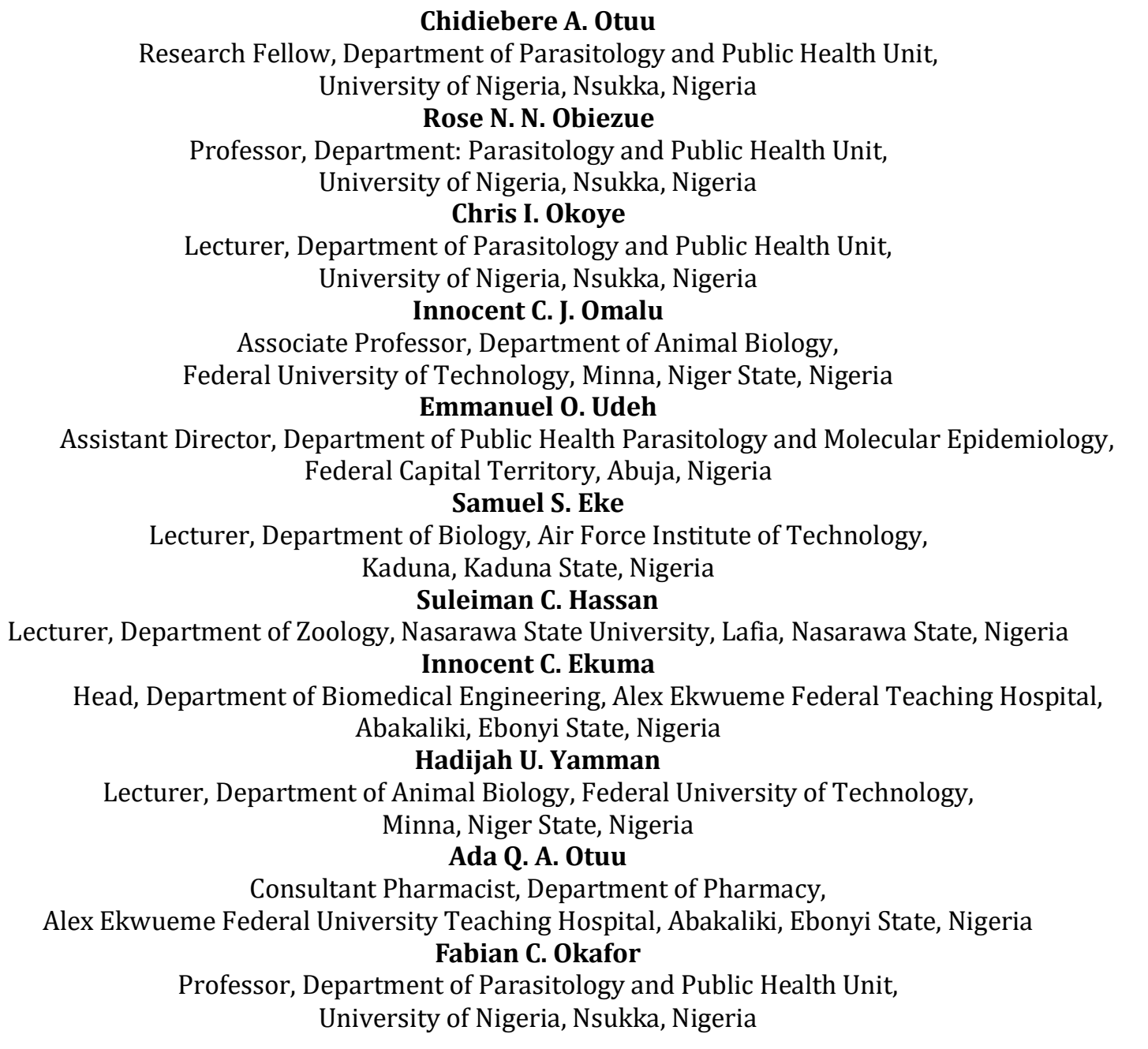 \\
\hline
\end{tabular}

\section{Abstract :}

This study, which is part of a project on the antimalarial potential of different extracts of Alstonia boonei plant parts, was carried out to determine the antimalarial property, chemical constituents and toxicity level of Alstonia boonei aqueous stem bark extract in white albino mice infected with Plasmodium berghei. The extract exhibited substantial dose dependent antimalarial property as shown by the suppressive effect $(41.48 \%, 52.67 \%$ and $69.82 \%$ for 100,200 and $400 \mathrm{mgkg}^{-1}$ body weights) prophylactic effect (48.69\%, 54.37\% and 62.63\% for 100, 200 and $400 \mathrm{mgkg}^{-1}$ body weights) and curative effect (52.63\%, 63.55\% and $68.82 \%$ for 100, 200 and $400 \mathrm{mgkg}^{-1}$ body weights) in white albino mice infected with Plasmodium berghei. The results of the antimalarial tests were significantly different compared to the negative control at $P<0.05$. Phytochemical screening of the extract revealed that the plant contains chemical constituents including tannins, flavonoids, steroids, phenols, alkaloids, saponins, glycosides and terpenoids. The toxicity test indicated that the extract is safe up to the lethal dose of $5000 \mathrm{mg} /$ body weight. From the results, the extract possesses important chemical constituents which are safe and exhibit good antimalarial property. This calls for further study of the extract as a potential antimalarial drug target.

Keywords: Antimalarial property, chemical constituent, toxicity, lethal dose, plasmodium berghei, suppressive, prophylactic, curative 


\section{Introduction}

Malaria still remains a major public health concern and is a major cause of mortality in areas where it is endemic $[1,2,3]$. The search for new antimalarial agents and drugs has been intensified due to the emergence of resistant strains of Plasmodium falciparum to the currently used antimalarial drugs $[4,5,6,7]$.

Many cultures throughout the world still rely on indigenous medicinal plants for their primary health care needs [8]. Products from nature play important roles as leads for the discovery and development of new drugs [9]. Plants have proved to be sources of important new drugs. Drugs for treating malaria such as quinine and artemisinin came from plants. The first antimalarial drug was quinine which was derived from the bark of the cinchona tree followed later by artemisinin which was isolated from Artemisia annua tree [10,11]. The success with these two plants derived drugs has resulted in the focus for potential antimalarial compounds for antimalarial drug development from traditional medicinal plants. One of such plants that has been focused on for its antimalarial property is Alstonia boonei.

Alstoniaboonei is a tree about 25-40 m high with white latex. The trunk has a diameter of about $1.4 \mathrm{~m}$, with or without buttresses. It has a grey white or yellowish bark which can be smooth or scaly. Leaves occur in the whorls of 4-9. A. boonei parts have been used for the treatment of malaria and other forms of diseases in Nigeria and other West African Countries $[12,13]$. Several studies have reported the use of $A$. boonei in recipes to treat malaria $[14,15]$. The plant parts are rich in various bioactive components such as echitamidine, boonein, and loganin [16].

\section{Materials and Methods}

\subsection{Plant Material}

The stem bark of Alstonia boonei was obtained from Obollo Afor town in Enugu State, Nigeria. The plat part was authenticated by a botanist in the Department of Plant Science and Biotechnology, University of Nigeria Nsukka, Enugu State, Nigeria and given voucher number 7602.

\subsection{Animals}

White albino mice obtained from the Nigerian Institute of Medical Research Lagos; Nigeria were used for the study. Approval for use of the animals was obtained from the University of Nigeria Ethical Committee on the use of laboratory animals for research with approval number UNN-ERC/Z/9875 - 7/5/18. All animal tests followed the guidelines of the National Institute of health $(\mathrm{NIH})$ guide for the care and use of laboratory animals, NIH publication (volume 25, number 28), revised 1996.

\subsection{Parasite Strain}

The P. berghei NK65 chloroquine sensitive strain, which was obtained from the Nigerian Institute of Medical Research, Lagos, Nigeria and maintained in mice by serial passage, used for this study.

\subsection{Preparation of the Stem Bark}

The stem bark of $A$. boonei was washed and cut into small pieces. They were dried in open air for two weeks and then ground into powder with a mechanical blender.

\subsection{Extraction procedure}

$500 \mathrm{~g}$ of the ground fine powder obtained was percolated in $1600 \mathrm{~mL}$ of water for $72 \mathrm{~h}$ after which it was filtered. This was followed by evaporating the filtrate collected to dryness using a temperature-regulated water bath pre-set at $40^{\circ} \mathrm{C}$ to yield the extract concentrate which was stored in the refrigerator at $4{ }^{\circ} \mathrm{C}$ prior to use.

\subsection{Phytochemical Test}

Standard chemical tests were done in order to determine the presence of chemical constituents in the extract [17].

\subsection{Toxicity Test}

The toxicity test of the extract was carried out using the methods described by Lorke 1983 [18]. The vehicle for the aqueous extracts administration to experimental mice was distilled water. A 4-hour test period was done after which mice were divided into groups of three. The extract doses were calculated in reference to the body weight of the mice. Each mouse was then treated with a single oral dose of the extract. The administered doses were 5, 50, 300, 1200 and 1500

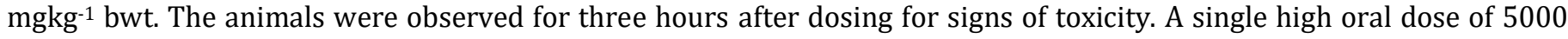

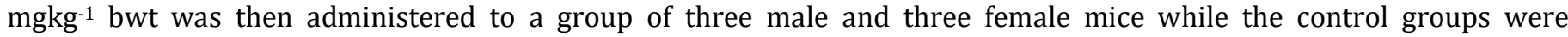
administered with the vehicle. The animals were given food one hour after the administration of the extracts. The animals were observed after 30 minutes after dosing which was followed by hourly observation for a period of 8 hours and the once a day for the next 13 days. Daily observations including physical change, signs of illness and mortality were recorded and surviving mice were weighed.

\subsection{Antimalarial Tests}

\subsubsection{Suppressive Activity}

The suppressive activity of the extract was evaluated in early Plasmodium berghei infection in white albino mice using the methods described by Peters 1967 [19]. Fifteen mice were randomly divided into five groups of three mice each. 
On the first day (D0), the mice were each infected with $10^{7}$ Plasmodiumberghei. Three hours later the infected mice were each treated orally with $10 \mathrm{mLkg}^{-1}$ body weight of the extract or $10 \mathrm{mgkg}^{-1}$ body weight of chloroquine. Group 1 , the negative control, was given $5 \mathrm{mLkg}^{-1}$ normal saline. Group 2, the positive control, was treated with $10 \mathrm{mgkg}^{-1} \mathrm{chloroquine}$ Groups 3 to 5 were treated with the extract.

The extract was administered orally at a dose of 100, 200 and $400 \mathrm{mg}$ extract $\mathrm{kg}^{-1}$. Treatment was carried out for four consecutive days (D0 - D3). The body weight of each mouse was measured on the first day (D0) and on the fifth day (D4). The body temperature was also taken before infection and three hours after infection (on D0) and then monitored daily to the fifth day (D4).

On the fifth day (D4), thin blood film was prepared from the tail blood of the mice. The thin blood film was fixed in methanol and stained with Giemsa to reveal parasitized erythrocytes. Parasitaemia was determined using light microscopy with 100X objective lens.

\subsubsection{Prophylactic Activity}

The prophylactic activity of the extracts was determined using the methods of Peters 1965 [20]. Another set of fifteen mice were randomly divided into five groups of three mice each. Group 1, the negative control, was given $5 \mathrm{mLkg}^{-1}$ normal saline. Group 2, the positive control, was treated with $10 \mathrm{mgkg}^{-1}$ chloroquine. Groups 3 to 5 were treated with the extract. The extract was administered orally at a dose of 100, 200 and $400 \mathrm{mg}$ extract $\mathrm{kg}^{-1}$. Treatment was carried out for three consecutive days (D0 - D2). On the fourth day (D3) the mice were inoculated with $10^{7} P$. berghei infected red blood cells. After 72 hours the level of parasitaemia was then determined using microscopy.

\subsubsection{Curative Activity}

The curative activity of the extract on established infections of Plasmodiumberghei on mice was assessed using the method earlier described by Ryley and Peters 1970 [21]. Another set of fifteen mice were infected with $10^{7} P$. berghei by intra peritoneal injection on the first day (D0). 72 hours later the mice were randomly divided into five groups of three mice each. Three groups of the mice (Groups 1 to 3) were treated orally with a dose of 100, 200 and $400 \mathrm{mg} \mathrm{kg}^{-1} \mathrm{body}$ weight of the extract. The negative control group (Group 4) was given $5 \mathrm{mLkg}^{-1}$ normal saline while the positive control group (Group 5) was treated with $10 \mathrm{mgkg}^{-1}$ chloroquine.

The treatments with the extract and drug were done once daily for five days. Parasitaemia levels was checked each day by preparing Giemsa-stained thin smears from blood samples collected from the tail of the mice and examined under the microscope. The body weight and temperature were taken before infection (D0) and from the fourth day (D3) to the eight day (D7). The mean survival time (MST) of the mice in each treatment group was determined over a period of 29 days (D0 - D28) by dividing the number of days each mouse survived with the total number of days and multiplying by 100.

\section{Results}

\subsection{Phytochemical Analysis}

The result of the phytochemical analysis revealed that the extract contains important compounds including tannin, flavonoid, steroid, pheno, alkaloids, saponin, glycoside and terpenoid. Tannin, steroid and phenol showed the highest intensity followed by flavonoid, alkaloid, saponins, glycoside and terpenoid. The result of the qualitative analysis of the extract is shown in Table 1 while the result of the quantitative analysis is shown in Table 2 and Figure 1.

\begin{tabular}{|c|c|c|c|c|c|c|c|c|}
\hline Extracts & Tannin & Flavonoid & Steroid & Phenol & Alkaloid & Saponin & Glycoside & Terpenoid \\
\hline Leaf Ethanol & ++ & + & ++ & ++ & + & + & + & + \\
\hline
\end{tabular}

Table 1: Results of the Qualitative Phytochemical Analysis of A. Boonei Aqueous Stem Bark Extract

Legend: + = Low; ++ = Moderate; +++ = High

\begin{tabular}{|c|c|c|c|c|c|c|c|c|}
\hline Compound & Tannin & Flavonoid & Steroid & Phenol & Alkaloid & Saponin & Glycoside & Terpenoid \\
\hline $\begin{array}{c}\text { Composition } \\
(\mathrm{Mg} / 100 \mathrm{~g})\end{array}$ & 312.05 & 162.581 & 3.158 & $\begin{array}{c}580.71 \\
8\end{array}$ & 64.956 & 0.578 & 126.848 & 153.05 \\
\hline
\end{tabular}

Table 2: Results of the Quantitative Phytochemical Analysis of a. Boonei Aqueous Stem Bark Extract 


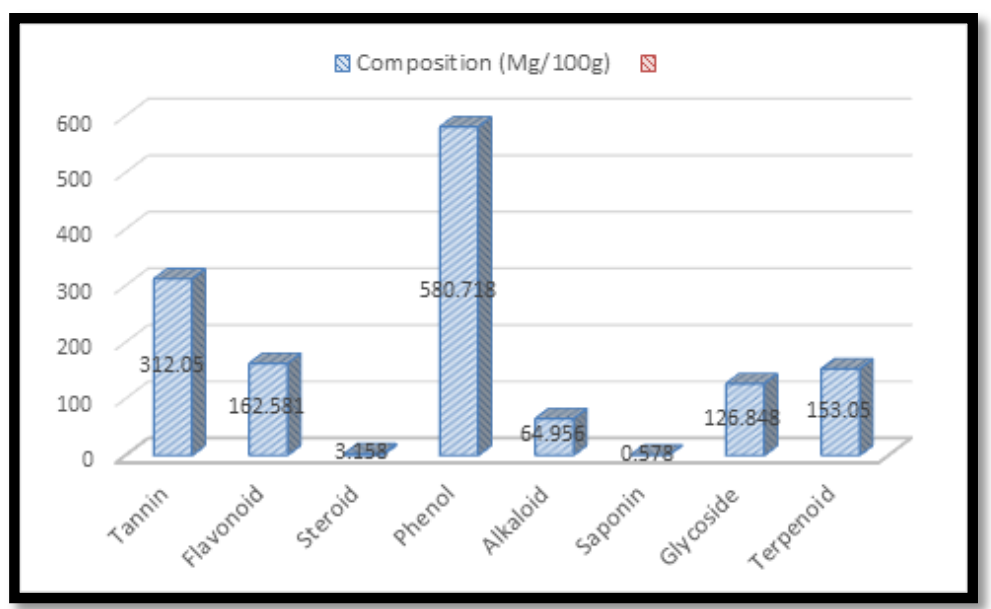

Figure 1: Results of the Quantitative Phytochemical Analysis of A. Boonei Aqueous Stem Bark Extract

\subsection{Acute Toxicity Studies}

It was observed that there was no mortality in all the doses used for the toxicity test which was 5, 50, 300, 1200 and $1500 \mathrm{mgkg}^{-1}$ body weight during the four days the treated mice were observed. This was an indication that the extract was not toxic. For the acute toxicity test of the extract, at the doses of 1500 and $5000 \mathrm{mgkg}^{-1}$ body weight, signs observed in the tested mice included licking of the paws, stretching, salivation and a reduction in activity. The oral median lethal dose (LD50) was determined to be greater than 5000 mgkg_1.

\subsection{Antimalarial Tests}

The suppressive test of ethanolic stem bark extract of $A$. boonei revealed a significant suppression, at $\mathrm{P}<0.05$, on the fourth day of the test by the extract. The suppressive activity was dose dependent with a suppression of $41 . .48 \%$ for $100 \mathrm{mgkg}^{-1}$ body weight, $52.67 \%$ for $200 \mathrm{mgkg}^{-1}$ body weight and $69.82 \%$ for $400 \mathrm{mgkg}^{-1}$ body weight respectively, as compared to the control, $5 \mathrm{mgkg}^{-1}$ body weight chloroquine, with a chemo suppression of $97.34 \%$. The results were significantly different from the negative control at $\mathrm{P}<0.05$. Table 3 and Figure 2 below show the results of the suppressive effect of ethanolic stem bark extract of $A$. boonei and chloroquine in mice infected with Plasmodium berghei.

\begin{tabular}{|c|c|}
\hline Treatments & Suppression (\%) \\
\hline Distilled water 5mlkg-1 & 0.00 \\
\hline Extract 100mgkg-1 & 41.48 \\
\hline Extract 200mgkg-1 & 52.67 \\
\hline Extract 400mgkg-1 & 69.82 \\
\hline Chloroquine 5mgkg-1 & 97.34 \\
\hline
\end{tabular}

Table 3: Suppressive Effect of Aqueous Stem Bark Extract of A. Boonei and Chloroquine in Mice Infected With Plasmodium Berghei

Significantly Different from the Control at $P<0.05$

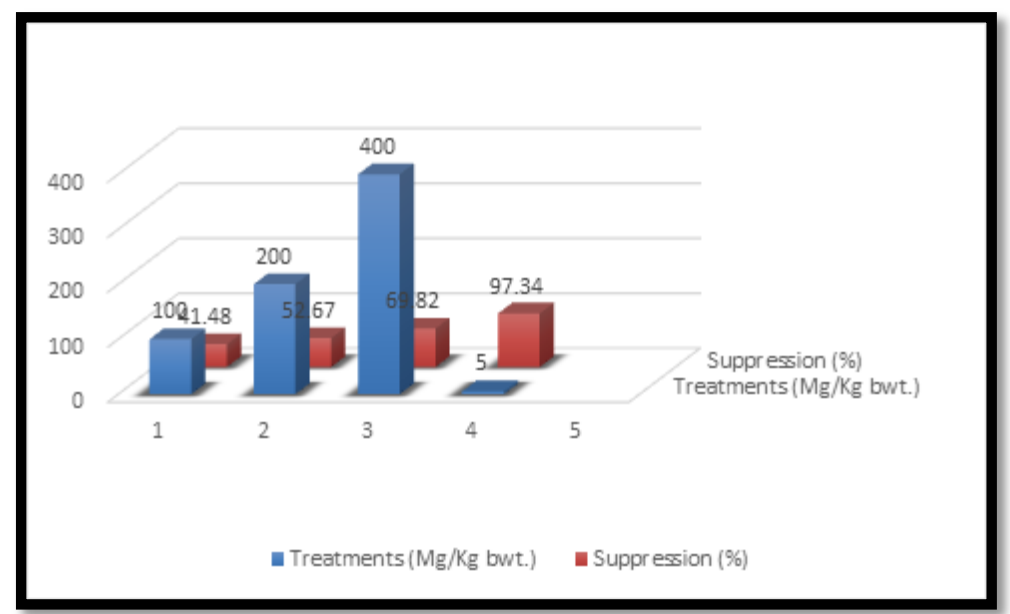

Figure 2: Suppressive Effect of Aqueous Stem Bark Extract of A. Boonei and Chloroquine in Mice Infected with Plasmodium Berghei

The prophylactic test of the aqueous stem bark extract produced a dose dependent reduction in 
parasitaemia levels of $48.69 \%$ for $100 \mathrm{mgkg}^{-1}$ body weight, $54.37 \%$ for $200 \mathrm{mgkg}^{-1}$ body weight and $62.63 \%$ for $400 \mathrm{mgkg}^{-1}$ body weight while $5 \mathrm{mgkg}^{-1}$ body weight chloroquine produced $95.45 \%$ reduction in levels of parasitaemia. The results were significantly different from the negative control at $\mathrm{P}<0.05$. The reduction in parasitaemia by the extract indicates that the extract possesses schizonticidal activity in blood. Table 4 and Figure 3 below show the results of the prophylactic effect of aqueous stem bark extract of A.boonei and chloroquine in mice infected with Plasmodium berghei.

\begin{tabular}{|c|c|}
\hline Treatments & Suppression (\%) \\
\hline Distilled water $5 \mathrm{mlkg}^{-1}$ & 0.00 \\
\hline Extract $100 \mathrm{mgkg}^{-1}$ & 48.69 \\
\hline Extract $200 \mathrm{mgkg}^{-1}$ & 54.37 \\
\hline Extract $400 \mathrm{mgkg}^{-1}$ & 62.63 \\
\hline Chloroquine $5 \mathrm{mgkg}^{-1}$ & 95.45 \\
\hline
\end{tabular}

Table 4: Prophylactic Effect of Aqueous Stem Bark Extract of A. Boonei and Chloroquine in

Mice Infected with Plasmodium Berghei

Significantly Different from the Control at $P<0.05$

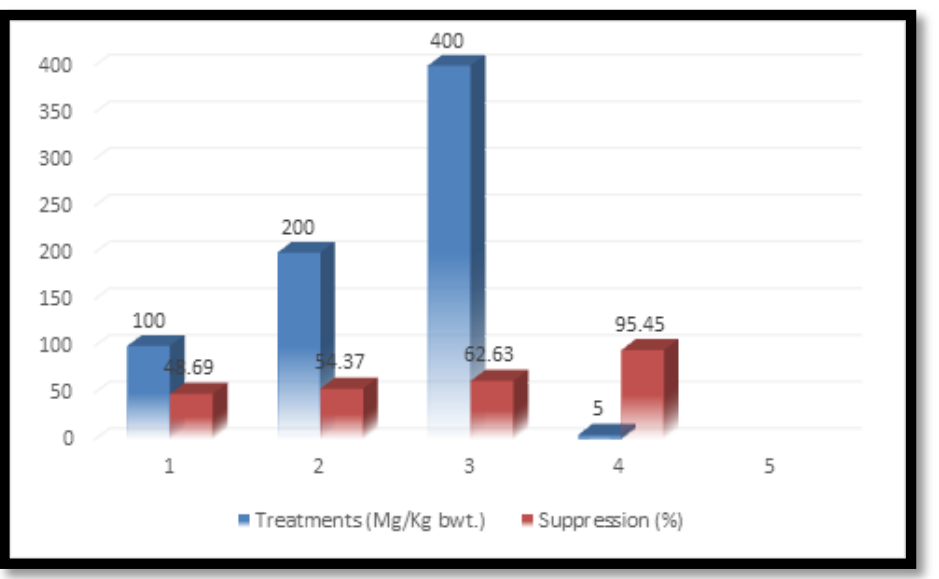

Figure 3: Prophylactic Effect of Aqueous Stem Bark Extract of A.Boonei and Chloroquine in Mice Infected with Plasmodium Berghei

For the curative test of the stem bark ethanolic extract, it was observed that the extract produced a significant dose dependent reduction $(\mathrm{P}<0.05)$ in the levels of parasitaemia in the groups treated with the extract. On the seventh day of the curative test the extract showed an average percentage parasitaemia suppression of $52.63 \%$, for $100 \mathrm{mgkg}^{-1}$ body weight, $63.55 \%$ for $200 \mathrm{mgkg}^{-1}$ body weight and $68.82 \%$ for $400 \mathrm{mgkg}^{-1}$ body weight while mgkg-1 body weight chloroquine produced a reduction in parasitaemia of $94.63 \%$. The results were significantly different from the control at $\mathrm{P}$ $<0.05$. Table 5 and Figure 4 below show the results of the curative effect of the ethanolic stem bark extract of $A$.boonei and chloroquine in mice infected with Plasmodiumberghei.

\begin{tabular}{|c|c|}
\hline Treatments & Suppression (\%) \\
\hline${\text { Distilled water } 5 \mathrm{mlkg}^{-1}}^{-1}$ & 0.00 \\
\hline Extract 100mgkg-1 & 52.63 \\
\hline Extract 200mgkg-1 & 63.55 \\
\hline Extract 400mgkg-1 & 68.82 \\
\hline${\text { Chloroquine } 5 \mathrm{mgkg}^{-1}}^{-1}$ & 94.63 \\
\hline
\end{tabular}

Table 5: Curative Effect of Ethanolic Stem Bark Extract of A. Boonei and

Chloroquine in Mice Infected with Plasmodium Berghei

Significantly Different From the Control at $P<0.05$ 


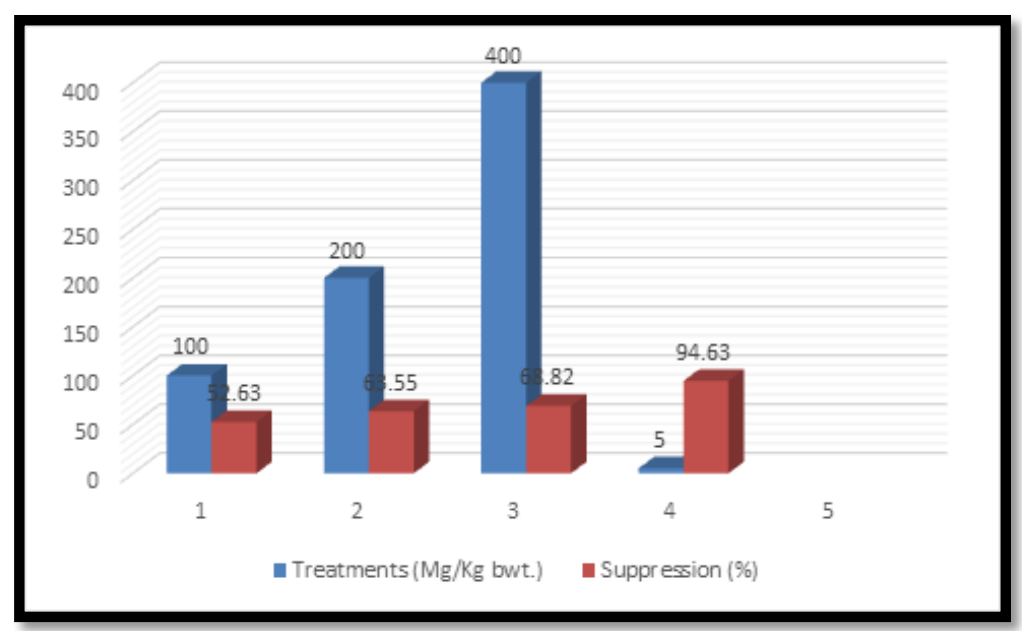

Figure 4: Curative Effect of Ethanolic Stem Bark Extract of A. Boonei and Chloroquine in Mice Infected with Plasmodium Berghei

\section{Discussion and Conclusion}

The result of the phytochemical test of aqueous stem bark extract of Alstoniaboonei showed the presence of tannin, flavonoid, steroid, phenols, alkaloid, saponin, glycoside and terpenoid. The presence of these chemicals in plants has been reported in other studies [22, 23, 24]. The presence of alkaloid in the extract may contribute to its antimalarial activity. Alkaloids present in plants have been reported to contribute to the antimalarial activities of the plants [25, 26,]. Toxicity test of the extract is similar to that in other toxicity studies on Alstoniaboonei extracts with no mortalities at the doses treated and the lethal dose was also observed to be greater than $5000 \mathrm{mgkg}^{-1}[27,28]$.

In the antimalarial tests of this study, the results obtained are similar to the results from other studies carried out on Alstonia boonei plant extracts [29, 30].

From the results obtained from this study, it is concluded that the aqueous stem bark extract of Alstoniaboonei has a good potential as an antimalarial drug target and should be further studied and positioned for drug development.

\section{References}

i. World Health Organization (WHO). Word malaria Report 2019. World Health Organization Geneva. Available at https://www.who.int/publications/i/item/world-malaria-report-2019. Accessed December 20

ii. Omalu ICJ, Olayemi IK, Otuu CA, et al. Entomological and parasitological indices of malaria transmission in Tungan-Goro and Gbaiko communities in Minna, Niger State, Nigeria. The Zoologist 2015, 13:1-5.

iii. Eke SS, Omalu ICJ, Olayemi IK, et al. Malaria Parasitaemia among Patients Attending General Hospital Minna, North Central Nigeria. Journal of Bioscience and Biotechnology Discovery 2018, 3(11):78-82.

iv. Dondorp AM, Nostern F, Yi P, et al. Artemisinin resistance in Plasmodiumfalciparum malaria. New England Journal of Medicine 2009, 361:455-467.

v. Miotto O, Almagro-Garcia J, Manske M, et al. Multiple population of artemisinin-resistant Plasmodium falciparum in Cambodia. Nature Genetics 2013, 45(6): 648-665.

vi. Ajayi NA, Ukwaja KN. Possible artemisinin-based combination therapy resistant malaria in Nigeria: a report of three cases. Revista da sociedade Brasileira de Medicina Tropical 2013, 46(4): 525-527.

vii. Otuu CA, Eke SS, Omalu IC, et al. Prevalence of malaria infection among persons seeking treatment from private drug retailers in North Central Nigeria. Journal of Public Health and Diseases2019, 2(1):1-6.

viii. Farnworth NR, Akerele ON, Bingel AS, et al. Medicinal plants in therapy. Bull World Health Organ 1985, 63(6):965-981.

ix. Newman DJ, Cragg GM, Shader KM. Natural products as sources of new drugs over the period 1981-2002. Journal of Natural Products 2003, 66:1022-1037.

x. Basco LK, Mitaku AL, Skaltsounis N, et al. In vitro activities of and acridone alkaloids against Plasmodiumfalciparum. Antimicrobial Agents Chemotherapy 1994, 38:1169-1171.

xi. Uzor PF, Prasasty VD, Agubata CO. Natural Products as Sources of Antimalarial Drugs. Evidence-Based Complementary and Alternative Medicine2020, Article ID 9385125.

xii. Olajide OA, Awe SO, Makinde JM, et al. Studies on the anti-inflammatory, antipyretic and analgesic properties of Alstoniaboonei stem bark. Journal of Ethnopharmacology 2000, 71(1-2):179-180.

xiii. Iyiola OA, Tijani AY, Lateef KM. Antimalarial Activity of Ethanolic Stem Bark Extract of Alstonia boonei in Mice. Asian Journal of Biological Sciences 2011, 4(3):235-243.

xiv. Omoya FJ, Oladipupo K, Abe A, et al. Bioactivity, Qualitative and Quantitative Components of Alstoniaboonei Leaf Extracts on Anopheles Mosquito Larvae in Nigeria. Journal of medicine and Bioengineering. 2012, 1(1):39.

xv. Idowu OA, Soniran OT, Ajana 0, et al. Ethnobotanical Survey of Antimalarial oil plants used in Ogun State Southwest, Nigeria. African Journal of Pharmacy and Pharmacology 2010, 4:55-60. 
xvi. Adotey JPK, Adukpo GE, Boahem YO, et al. A Review of the Ethnobotany and Pharmacological Importance of Alstonia boonei De Wild (Apocynaceae). International Scholarly Research Network Pharmacology 2012, 587 160.

xvii. Roghini R, Vijayalakshmi K. Phytochemical Screening, Quantitative Analysis of Flavonoid and Minerals in Ethanolic Extract of Citrus Paradisi. Journal of Pharmaceutical Sciences and Research 2018, 9(11):4859-4864.

xviii. Lorke D. A new approach to acute toxicity testing. Archives of Toxicology 1983, 54:275-287.

xix. Peters W. Rational methods in the search for antimalarial drugs. Transactions of the Royal Society of Tropical Medicine and Hygiene 1967, 61:400-410.

xx. Peters W. Drug resistance in Plasmodiumberghei. Vincke and Lips, 1948; 1. Chloroquine resistance. Experimental Parasitology 1965, 17:80-89.

xxi. Ryley JF, Peters W. The antimalarial activity of some quinolone esters. Ann. Trop. Med. Parasitol. 1970, 84:209222.

xxii. Oigiangbe ON, Igbinosa IB, Tama M. Bioactivity of extracts of Alstoniaboonei (Apocynaceae) De Wild Stem Bark against Marucavitrate (Lepidoptera: Pyralidae) Fabricus. Advances in Science and Technology 2007, 1(1):67-70.

xxiii. Batista R, De Jesus SA, De Oliveira AB. Plant derived antimalarial agents: New leads and efficient Phytomedicines. Part II. Non-Alkaloidal natural products. Molecules2009, 14:3037-3072.

xxiv. Imam AA, Atiku MK, Muhammad IU, et al. In vitro Antimalarial Activity of Solvents Extracts of Alstonia boonei Stem Bark and Partial Characterization of Most Active Extract(s). Journal of Pharmaceutical Research International 2017, 19(2):1-10.

xxv. Ajaiyeoba EO, Abiodun 00, Falade MO, et al. In vitro cytotoxicity studies of 20 plants used in Nigerian antimalarial ethnomedicine. Phytomedicine 2006, 13(4):295-298.

xxvi. Omoya F, Oyebola TF. Antiplasmodial activity of stem bark and leaves of Alstonia boonei (De Wild). Journal of Microbiology and Experimentation 2019, 7(5):241-245.

xxvii. Akinmoladun AC, Ibukum EO, Afor E, et al. Chemical constituents and antioxidant activity of Alstoniaboonei. African Journal of Biotechnology 2007, 6(10):1197-1201.

xxviii. Obiagwu MO, Ihekwerem CP, Ajaghaku DL, et al. The Useful Medicinal Properties of the Root-Bark Extract of Alstonia boonei (Apocynaceae) May Be Connected to Antioxidant Activity. International Scholarly Research Network Pharmacology 2014, 741478.

xxix. Olanlokun JO, Bolaji OM, Agbedahunsi JM, et al. Therapeutic effects of various solvent fractions of Alstonia boonei (apocynaceae) stem bark on Plasmodiumberghei -induced malaria. African Journal of Medicine and Medical Sciences2012, 14:27-33.

xxx. Afolabi OJ, Abejide AE. Antiplasmodial activities of Morindalucida (Benth) and Alstoniaboonei (De wild) in mice infected with Plasmodiumberghei. Bulletin of Natural Research Centre 2020, 44:85. 